\title{
DESIGN AND PERFORMANCE OF WIDEBAND, LOW-NOISE, MILLIMETER-WAVE AMPLIFIERS FOR MICROWAVE ANISOTROPY PROBE RADIOMETERS
}

\author{
Marian W. Pospieszalski, ${ }^{*}$ Edward J. Wollack, ${ }^{* *}$ Nancyjane Bailey, ${ }^{* * *}$ Dorsey Thacker," \\ John Webber, ${ }^{*}$ Loi D. Nguyen, ${ }^{\dagger}$ Minh Le, ${ }^{\dagger}$ Mark Lui ${ }^{\dagger}$ \\ National Radio Astronomy Observatory, ${ }^{*}$ Charlottesville, VA 22903 \\ HRL Laboratories, ${ }^{\dagger}$ Malibu, CA 90625
}

\begin{abstract}
Differential pseudo-correlation radiometers covering 20-25 GHz, 28-37 GHz, 35-46 GHz, 53-69 $\mathrm{GHz}$ and 82-106 $\mathrm{GHz}$ are used in the Microwave Anisotropy Probe (MAP) mission to be launched in late 2000. This paper describes the design, performance and manufacturing of 140 InP HFET amplifiers suitable for cryogenic cooling which exhibit low noise performance and complex gain match over the given radiometer bandwidths (typical noise temperature of $90 \mathrm{~K}$, or $1.2 \mathrm{~dB}$ noise figure, for $\mathrm{W}$-band amplifier at 80 K ambient).
\end{abstract}

\section{INTRODUCTION}

The Microwave Anisotropy Probe (MAP) to be launched in late 2000 is designed to make a full-sky map of the cosmic microwave background (CMB) with $20 \mu \mathrm{K}$ sensitivity per $.3^{*} .3^{\circ}$ pixel during the two-year lifetime of the mission. Differential pseudo-correlation radiometers covering $20-25 \mathrm{GHz}, 28-37 \mathrm{GHz}, 35-46 \mathrm{GHz}, 53-69 \mathrm{GHz}$ and $82-106 \mathrm{GHz}$ are used in this mission. A schematic view of a MAP radiometer is shown in Fig.1 [1]. The input optics, horns, orthomode transducers (OMT), input hybrid T's and input amplifiers with about $30 \mathrm{~dB}$ of gain are passively cooled to about $80 \mathrm{~K}$. The other amplifiers (needed to achieve about $-23 \mathrm{dBm}$ signal level at the square law detectors), phase switches, output hybrid T's and bandpass definition filters are kept at about $300 \mathrm{~K}$. A major design challenge was to achieve a complex gain match between two separate signal paths while maintaining the lowest noise and flat gain over the required bandwidth. This led to the amplifier electrical specifications listed in Table I, further augmented by the limits on mass, power dissipation and requirements of space qualification procedures. The following sections give brief descriptions

\footnotetext{
"The National Radio Astronomy Observatory is a facility of the National Science Foundation operated under cooperative agreement by Associated Universities, Inc. ${ }^{* *}$ NRAO, now at Goddard Space Flight Center, Greenbelt, MD. ${ }^{* * *}$ NRAO, now at Corning, Inc., Corning, NY.
}

of the amplifier design process, manufacturing procedures and measured performance of about 140 amplifiers. Previous published results [2]-[6],[10] establish the achievable performance of InP HFET amplifiers. This paper describes for the first time the performance of a relatively large number of amplifiers for a space-based system which required very repeatable noise and complex gain response among the set.

\section{DESIGN}

The MAP amplifier specifications required the use of .1 $\mu \mathrm{m}$ gate length, InAlAs/InGaAs/InP HFET's. More mature GaAs-based technologies could not guarantee the noise performance required by the scientific goals of the mission or satisfy the requirement for the total power dissipation needed to achieve the required gain per channel and maintain the cold station temperature. At the beginning of the project in July 1996, a hybrid "chip-andwire" MIC realization was chosen over that of using MMIC's. There were several reasons for that decision. In 1996 there was no working example of a MMIC-based cryogenic receiver, but there were already several radio astronomy receivers employing InP HFET MIC amplifiers at $\mathrm{K}_{\mathrm{a}}$ - and Q-bands in use. A complex gain matched pair of $60-90 \mathrm{GHz}$ cryogenically-coolable amplifiers had already been demonstrated [2]-[4]. Also, the project schedule requiring deliveries of first amplifiers within a year made the choice of MMIC technology untenable. Consequently, the MIC approach developed over the years at NRAO [2]-[4], [7] was adopted while the component selection, machining, plating, bonding and other assembly procedures were modified to meet the space-qualification requirements.

The InP HFET's having . $1 \mu \mathrm{m}$ gate length were developed and delivered by HRL Laboratories [8]. Devices of two different gate widths were employed, $100 \mu \mathrm{m}$ wide for K-, $\mathrm{K}_{\mathrm{a}}$ - and Q-band amplifiers and $50 \mu \mathrm{m}$ wide for $\mathrm{V}$ - and Wband amplifiers. All amplifiers were designed with CAD 
tools with special emphasis on addressing the microwave design and package design concurrently. For the purpose of noise modeling at room and cryogenic temperatures, the noise model of [9] was employed as described in [2]-[3]. All amplifiers have at their input and output full waveguide bandwidth, E-plane probe waveguide-to-microstrip transitions (IRL $>18 \mathrm{~dB}$ ). The input, output and interstage microstrip networks use pure PTFE, .003" thick substrates with the coupling capacitors realized using .003" quartz substrates. These networks were designed to achieve low average noise temperature as well as flat gain across the band. The bias networks use a variety of capacitors and resistors connected by bondwires to assure stability and desired out-of-band response. When necessary, the distributed models of these networks were used in the design process.

The gain specifications required four stages of amplification for $\mathrm{K}-, \mathrm{K}_{\mathrm{a}}$ - and Q-band amplifiers, five for $\mathrm{V}$-band amplifiers and six for W-band amplifiers. The design of both room temperature and cold amplifiers was exactly the same. This allowed for greater flexibility in obtaining the best noise performance and complex gain match in both channels of a radiometer by proper selection of amplifier pairs. Upon final selection, only the bias had to be set for operation at a particular temperature.

The radiometer's performance is strongly dependent on amplifier gain fluctuations due to intrinsic as well as extrinsic factors. The 1/f-like random gain fluctuations related to 1/f noise of the HFET's were addressed in the previous paper [4]. In order to minimize the susceptibility of amplifier gain to the temperature variations, a constant gate voltage bias scheme was employed. As shown in [3], this type of supply reduces the susceptibility of gain variations at room temperature and virtually eliminates it in the 80 to $95 \mathrm{~K}$ range, the desired operating temperature of the cold part of the radiometers.

\section{MEASUREMENTS}

The noise measurements were carried out in a receiver setting using "hot" (297 K) and "cold" (78 K) loads placed in front of a horn connected to an amplifier which, in turn, was connected to a room temperature mixer with swept LO frequency. For cold measurements, both the amplifier and the horn were cooled to $80 \mathrm{~K}$, and, consequently the "hot" and "cold" loads were "viewed" through a vacuum window of a dewar. The receiver noise temperatures measured in this way are shown in Fig. 2. Room temperature data contain all deliverable amplifiers while the data at $80 \mathrm{~K}$ include only the data for the amplifiers designated for cold operation. Repeatability of both cryogenic and room temperature performance is excellent.
An example of gain at $300 \mathrm{~K}$ and $80 \mathrm{~K}$ of $15 \mathrm{~K}_{\mathrm{a}}$-band amplifiers is shown in Fig. 3. The corresponding phase tracking plots for $11 \mathrm{~K}_{\mathrm{a}}$-band amplifiers, both at room and cryogenic temperatures, are shown in Fig. 4. The plots show the phase difference between a phase response of a particular amplifier and the average phase response computed for the set of 11 amplifiers. Another example of gain measurements of $40 \mathrm{~W}$-band amplifiers is shown in Fig. 5. The phase tracking plots of $30 \mathrm{~W}$-band amplifiers at $297 \mathrm{~K}$ and $23 \mathrm{~W}$-band amplifiers at $80 \mathrm{~K}$, computed as in the $\mathrm{K}_{\mathrm{a}}$-band case, are shown in Fig. 6.

\section{CONCLUSIONS}

The design and performance of a series of cryogenicallycoolable, InP HFET amplifiers for the MAP mission have been described. The amplifiers not only exhibit the stateof-the-art performance but also an excellent repeatability of noise temperature and complex gain sufficient for the construction of the phase switched pseudo-correlation radiometers with 20 percent relative bandwidth, even at the $\mathrm{W}$-band frequencies. The choice of hybrid MIC technology, dictated by the state-of-the-art of the less mature (at the time of decision) InP MMIC technology and also by schedule concerns has been validated. The advancements in InP MMIC design and technology will likely make a different choice appropriate for some future projects. Yet, in low volume, low budget, and some high performance applications, this approach could prove to be cost effective and schedule efficient for years to come.

\section{REFERENCES}

[1] C. L. Bennett et al., "Microwave Anisotropy Probe," A MIDEX Mission Proposal, Goddard Space Flight Center and Princeton University, Dec. 1995. Also see http://map.gsfc.nasa.gov.

[2] M. W. Pospieszalski, W. J. Lakatosh, L. D. Nguyen, M. Lui, T. Liu, M. Le, M. A. Thompson and M. J. Delaney, "Q- and E-Band Cryogenically-Coolable Amplifiers Using AlInAs/GaInAs/InP HEMT's," in Proc. 1995 IEEE MTT-S Int. Microwave Symp., Orlando, FL, pp. 1121-1124, May 1995.

[3] M. W. Pospieszalski, W. J. Lakatosh, E. Wollack, Loi D. Nguyen, Minh Le, Mark Lui and Takyiu Liu, "Millimeter-Wave Waveguide-Bandwidth Cryogenically-Coolable InP HEMT Amplifiers," in Proc. 1997 IEEE MTT-S Int. Microwave Symp., Denver, CO, pp. 1285-1288, June 1997.

[4] E. J. Wollack and M. W. Pospieszalski, "Characteristics of Broadband InP Millimeter-Wave Amplifiers for Radiometry, Proc. 1998 IEEE MTT-S Int. Microwave Symp. Digest, Baltimore, MD, pp. 669772, June 7-12, 1998. 
[5] S. Weinreb, R. Lai, N. Erickson, T. Gaier and J. Wielgus, "W-Band INP Wideband MMIC LNA With 30 K Noise Temperature," in Proc. 1999 IEEE MTTS Int. Microwave Symp., pp. 101-104, Anaheim, CA, June 1999.

[6] N. R. Erickson, R. M Grosslein, R. B. Erickson and S.Weinreb, "W-Band INP Wideband MMIC LNA With 30 K Noise Temperature," in Proc. 1999 IEEE MTT-S Int. Microwave Symp., pp.251-254, Anaheim, CA, June 1999.

[7] M. W. Pospieszalski, L. D. Nguyen, M. Lui, T. Liu, M. A. Thompson and M. J. Delaney, "Very Low Noise and Low Power Operation of Cryogenic AlInAs/GaInAs/InP HFET'S," in Proc. 1994 IEEE MTT-S Int. Microwave Symp., San Diego, CA, pp. 1345-1346, May 1994.

[8] L. D. Nguyen et al., "Manufacturability of $0.1-\mu \mathrm{m}$ Millimeter-Wave Low-Noise InP HEMT's," in Proc. 1993 IEEE MTT-S Int. Microwave Symp., pp. 345347, Atlanta, GA, June 1993.

[9] M. W. Pospieszalski, "Modeling of Noise Parameters of MESFET's and MODFET's and Their Frequency and Temperature Dependence," IEEE Trans. on Microwave Theory and Tech., vol. MTT-37, pp. 1340-1350, Sept. 1989.

[10] M. W. Pospieszalski and E. J. Wollack, "Characteristics of Broadband InP HFET MillimeterWave Amplifiers and Their Applications in Radio Astronomy Receivers," (invited) Proc. 2nd ESA Workshop on Millimeter-Wave Technology and Applications: Antennas, Circuits and Systems, MilliLab, Espoo, Finland, pp. 221-226, May 27-29, 1998.

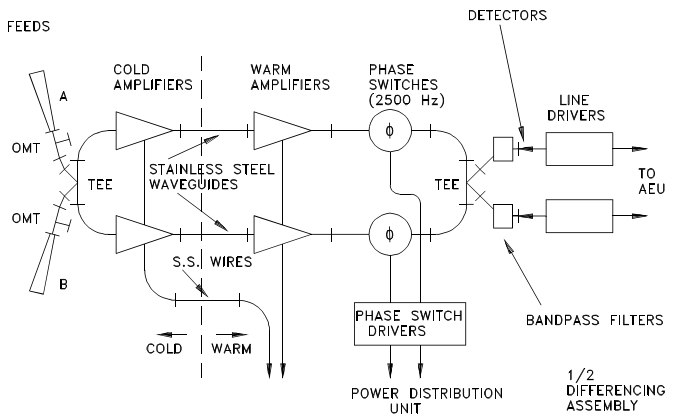

Fig. 1. Schematic of MAP pseudo-correlation radiometer.

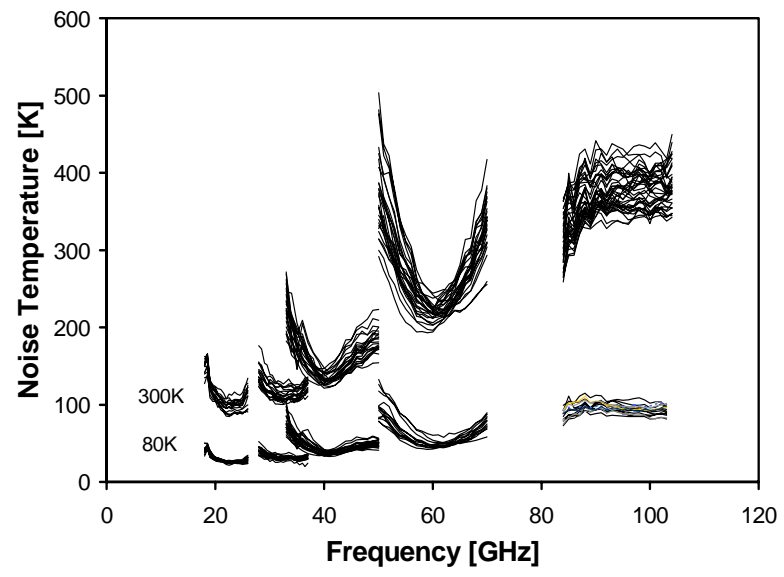

Fig. 2. Measured noise performance of all MAP amplifiers at room temperature and $80 \mathrm{~K}$.

TABLE I. NRAO MAP Amplifier - Technical Specification

\begin{tabular}{|c|c|c|c|c|c|c|}
\hline $\begin{array}{c}\text { Freq. } \\
\text { Band } \\
{[\mathrm{GHz}]}\end{array}$ & $\begin{array}{c}\text { InP } \\
{\left[\mu \mathrm{m}^{2}\right]}\end{array}$ & $\begin{array}{c}\text { Noise } \\
(80 / 300 \mathrm{~K}) \\
{[\mathrm{K}]}\end{array}$ & $\begin{array}{c}\text { Gain } \\
(80 / 300 \mathrm{~K}) \\
{[\mathrm{dB}]}\end{array}$ & $\begin{array}{c}\text { Gain } \\
\text { Flatness } \\
{[\mathrm{dB}]}\end{array}$ & $\begin{array}{c}\text { Phase } \\
\text { Tracking } \\
{[\mathrm{deg}]}\end{array}$ & $\begin{array}{c}\text { Power } \\
(80 / 300 \mathrm{~K}) \\
{[\mathrm{mW}]}\end{array}$ \\
\hline $20-25$ & $0.1 \times 100$ & $<27 / 100$ & $35 / 34$ & \pm 1.5 & \pm 15 & $<(24+9) / 45$ \\
\hline $28-37$ & $0.1 \times 100$ & $<40 / 145$ & $33 / 34$ & \pm 1.5 & \pm 15 & $<(24+9) / 45$ \\
\hline $35-46$ & $0.1 \times 100$ & $<50 / 180$ & $36 / 31$ & \pm 2.0 & \pm 20 & $<(24+9) / 45$ \\
\hline $53-69$ & $0.1 \times 50$ & $<80 / 300$ & $36 / 31$ & \pm 2.5 & \pm 20 & $<(30+9) / 45$ \\
\hline $82-106$ & $\begin{array}{c}0.1 \times 50 \\
\text { (unpassivated) }\end{array}$ & $<130 / 460$ & $35 / 29$ & \pm 3.0 & \pm 25 & $<(28+9) / 54$ \\
\hline
\end{tabular}




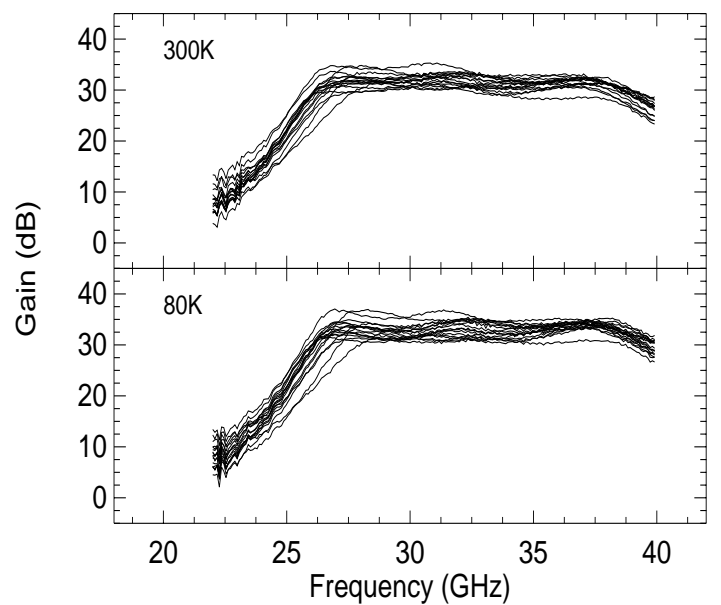

Fig. 3. Measured gain performance of $\mathrm{K}_{\mathrm{a}}$-band amplifiers.

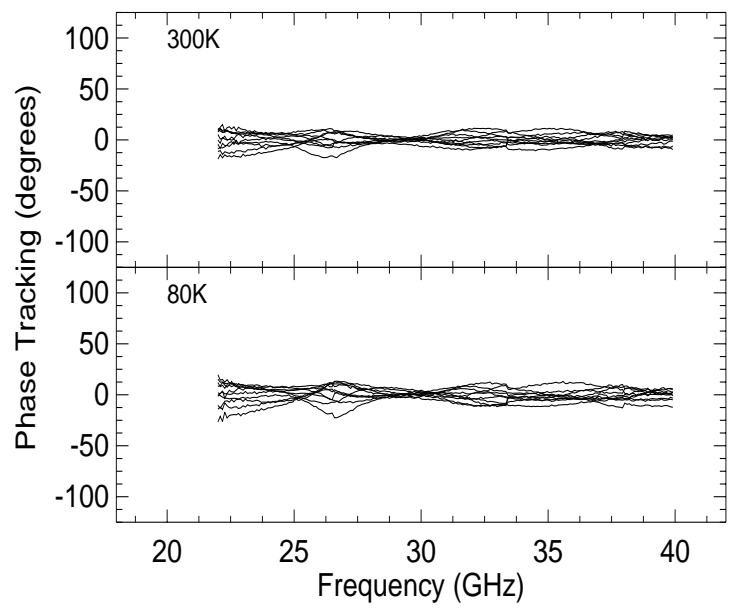

Fig. 4. Phase tracking of $11 \mathrm{~K}_{\mathrm{a}}$-band amplifiers at $300 \mathrm{~K}$ and $80 \mathrm{~K}$.

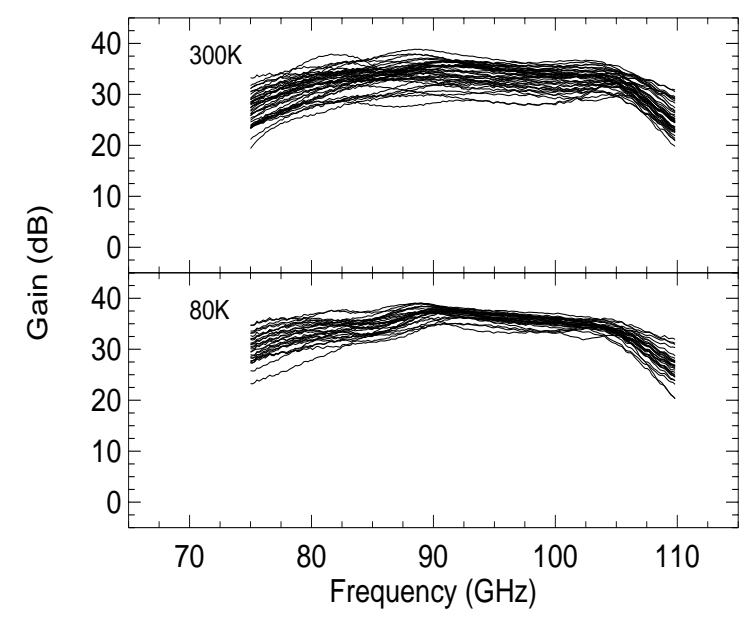

Fig. 5. Measured gain performance of W-band amplifiers.

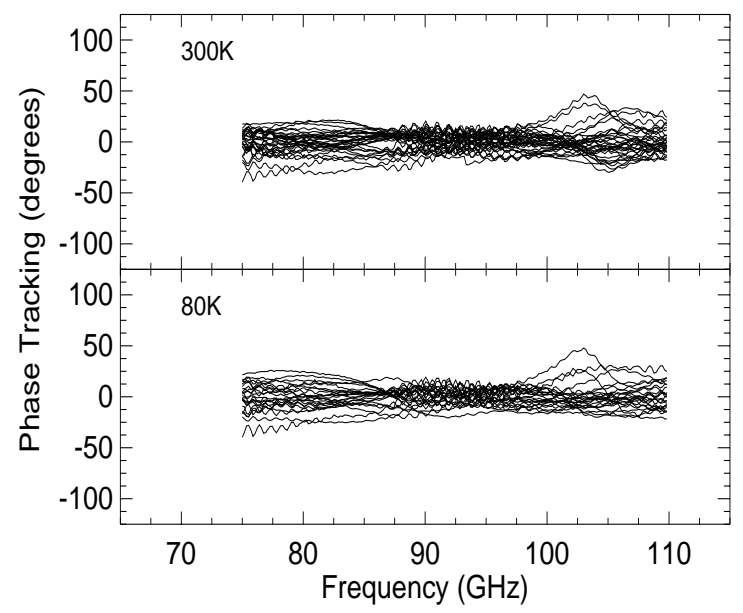

Fig. 6. Phase tracking of $30 \mathrm{~W}$-band amplifiers at $300 \mathrm{~K}$ and $23 \mathrm{~W}$-band amplifiers at $80 \mathrm{~K}$. 